\title{
EL DERECHO DEL CONSUMIDOR Y SUS EFECTOS EN EL DERECHO CIVIL FRENTE A LA CONTRATACION DE CONSUMO EN EL MERCADO
}

\author{
DURAND CARRIÓN, Julio Baltazar ${ }^{83}$
}

\section{Resumen}

El fenómeno de la producción industrial, la anonimización y despersonalización de los proveedores, la masificación de los consumidores y la proliferación de los contratos por adhesión, han dado lugar a la "Contratación de Consumo" y al crecer el comercio, obviamente las normas clásicas del Derecho Privado incorporadas en los códigos civiles de base romanista el Código Civil e influencia napoleónica, sin duda resultan ya insuficientes para regular las efectos jurídicos derivados de este tipo de contratos, en un mercado como el de hoy lleno de presiones crecientes y extendidas. Por lo tanto, podemos establecer que el Derecho del Consumidor es una disciplina singular, especializada y con cierta autonomía que no se ubica ni en el Derecho Privado, ni en el Derecho Comercial, ni el Derecho Civil, sino que constituiría una disciplina de carácter interdisciplinario y que está fortalecida de nuevos conceptos y que tiene además notas características importantes.

En este sentido el Derecho del Consumidor constituye un sistema global de normas, principios, instituciones e instrumentos consagrados por el ordenamiento jurídico a favor del consumidor para garantizar en el mercado una posición de equilibrio con los empresarios proveedores, en una relación de consumo y como destinatario final de los bienes y servicios adquiridos.

\section{Palabras clave:}

Contratación en masa, contratación de consumo, anonimización y despersonalización de los proveedores, Contrato por Adhesión, Cláusulas Generales de Contratación, Contratación Clásica, Protección del Consumidor, Contratante débil, Códigos Civiles

${ }^{83}$ Doctor en Derecho por la Pontificia Universidad Católica del Perú, Magister en Derecho Civil y Comercial por la Universidad de San Martín de Porres; Abogado por la Universidad de San Martín de Porres, Diplomados en Propiedad Intelectual, Derecho Internacioanl, Derecho Empresarial, y Gerencia. 


\section{EL DERECHO DEL CONSUMIDOR Y SUS EFECTOS EN EL DERECHO CIVIL FRENTE A LA CONTRATACION DE CONSUMO EN EL MERCADO}

SUMARIO: 1. Introducción. - 2. Contratación de consumo y contratación clásica. - 3. Contrato de Consumo. - 4. Crisis de la contratación clásica. - 5. Cambios que genera el Derecho Civil en el Derecho del Consumidor. - 6. Derecho Civil y el régimen jurídico de las clausulas generales de contratación y los contratos por adhesión. - 7. El Contratante Débil. - 8. Responsabilidad Civil en el ámbito del Derecho del Consumidor.- 9. Conclusiones.

\section{Introducción}

El Derecho del Consumidor y todo el movimiento pro consumerista mundial desde hace buen tiempo viene ejerciendo cierta influencia en las normas clásicas del Derecho Civil $\mathrm{y}$ en particular en materia contractual, la que se ha visto seriamente afectada en sus principios, por la evolución económica y social de nuestros tiempos y que han debilitado la permanencia e inmutabilidad histórica de las reglas establecidas sobre la base del Derecho Romano y la fuerte influencia del Código Civil Francés de 1804, entre otros.

Pero revisemos en qué consiste en esencia esta nueva disciplina llamada Derecho del Consumidor. En efecto, el Derecho del Consumidor constituye un sistema global de normas, principios, instituciones e instrumentos consagrados por el ordenamiento jurídico a favor del consumidor para garantizar en el mercado una posición de equilibrio con los empresarios proveedores, en una relación de consumo y como destinatario final de los bienes y servicios adquiridos.

El régimen especial del Derecho del Consumidor tiene tres elementos importantes: a) Consideración especial del sujeto consumidor, dentro de un determinado rol; b) Función de tutela; c) Carácter imperativo en materia de orden público.

En este contexto, llama particularmente la atención, la contratación de consumo, como una nueva modalidad que tiene una gran relación con el Derecho del Consumidor, sobre todo en la preocupación por el llamado contratante débil que no es una noción individual sino una categoría y una cualidad con la que se acude al contrato. La contratación de consumo es en cierto modo una contratación derivada de la contratación masiva cuyas expresiones más acabadas son el contrato por adhesión y las cláusulas generales de contratación y donde la teoría general de las obligaciones ha perdido vigencia en muchos de sus principios basados en una economía agraria y de pequeños comerciantes.

En el Derecho del Consumidor, la oferta, promoción y publicidad de los productos o servicios deben ajustarse a su naturaleza y las garantías ofrecidas darán lugar a obligaciones de los proveedores que serán exigibles por los consumidores o usuarios aun cuando no figuren en el contrato celebrado, o en el comprobante recibido. 
De otro lado, la mayoría de legislaciones de protección del consumidor de Latinoamérica y en especial el Código de protección y Defensa del Consumidor del Perú, que contemplan los derechos de los consumidores establecen, que éstos tienen derecho a recibir de los proveedores toda la información necesaria para tomar una decisión o realizar una elección adecuada en la adquisición de productos. Asimismo, los consumidores tienen derecho a la protección contra métodos comerciales coercitivos o que impliquen desinformación o información equivocada de los productos o servicios.

Con las normas descritas anteriormente, podríamos decir que las disposiciones de carácter civil, presentes en casi todos los códigos latinoamericanos y europeos inclusive, estructurados sobre la base del Código Civil Napoleónico, se estarían derogando tácitamente, porque ya no se permitiría establecer cláusulas aprobadas administrativamente beneficiarias para la parte que la pre-redactó sin conocimiento de su contraparte. Es más, podrían quedar sin efecto aquellos artículos de los códigos referidos a las cláusulas generales de contratación por los cuales se presume una publicidad adecuada, teóricamente entendida, para dar paso a una defensa real del propio consumidor que trasciende el contenido a veces limitado e irreal, intencionalmente plasmado por el prototipo de hombre contractual que busca siempre asumir menores riesgos y obtener mayores beneficios. Así, ahora los consumidores pueden exigir el cumplimiento de las características inherentes al bien o servicio específico, teniendo derecho a una información adecuada y protección frente a mecanismos coercitivos que reflejen desinformación o información equivocada.

Para algunos tratadistas el Derecho del Consumidor ha derogado y desplazado al Derecho Civil en materia de contracción de consumo; sin embargo, nosotros tenemos una lectura distinta y en tal sentido creemos que el reciente Derecho del Consumidor ha complementado al Derecho Civil en la regulación de las complejas relaciones derivadas del fenómeno del consumo. En efecto, es preciso reconocer que el Derecho Civil creó figuras como el "Contrato por Adhesión" y las "Cláusulas Generales de Contratación" para facilitar el tráfico comercial, así mismo estableció figuras como la buena fe, los vicios de la voluntad, el saneamiento por los vicios ocultos, etc. y fueron estas las normas de justicia contractual que se aplicaron en un primer momento para resolver los eventuales problemas de información asimétrica que afectaban la voluntad de las partes; no obstante el fenómeno de la producción industrial, la anonimización y despersonalización de los proveedores, la masificación de los consumidores y la proliferación de los contratos por adhesión, dieron lugar a la "Contratación de Consumo" y al crecer el comercio, obviamente el Código Civil ya era insuficiente para regular las efectos jurídicos derivados de este tipo de contratos, porque dicho código estaba estructurado sobre otras bases, como la de la autonomía de la voluntad, el principio pacta sunt servanda, entre otros.

Es en este contexto que surge el Derecho del Consumidor como una disciplina jurídica que va ganando autonomía y que nace como una respuesta a este fenómeno sociojurídico propio del crecimiento del mercado y va construyendo su propio contenido, su propio objeto de estudio, sus propios principios, instituciones y procedimientos que de una u otra forma complementan el Derecho Civil en el tratamiento jurídico del consumo.

Podemos afirmar que el Derecho del Consumidor ha hecho una construcción especializada sobre la base de las instituciones que en su momento creó el Derecho Civil Clásico y que tuvieron su aplicación en un momento dado y que hoy ya no son aplicables porque la contratación de consumo exige un tratamiento distinto que supera lo establecido en el Código Civil, por lo que resulta saludable que la normatividad elaborada posteriormente 
efectivice el cumplimiento de disposiciones declarativas y se delimite en forma clara y taxativa los alcances de la protección al consumidor.

Es tarea ahora de legisladores, técnicos y especialistas, concordar y actualizar las normas sustantivas civiles; sobre todo ahora que la comunidad jurídica en general propone una modificación del código. Es pertinente ahora hacer un balance de lo favorable o desfavorable del mismo.

El ordenamiento civil clásico, no puede seguir manteniendo estructuras jurídicas atrasadas, sobre todo en la parte contractual y específicamente en los Contratos por Adhesión, donde las cláusulas generales deben ceder a las nuevas connotaciones del Derecho del Consumidor que han ido ganando terreno gracias a los modelos económicos imperantes, caso contrario la norma civil de contratos perderá vigencia social por estar desarraigada del contexto socio económico que paradójicamente regula, generando con ello conflictos de interés que precisamente el Derecho tiende hoy a evitar.

En este contexto es preciso analizar algunos temas relacionados con la contratación de consumo y su influencia en la contratación civil clásica.

\section{Contratación de consumo y contratación clásica}

El cambio de la dinámica económica y su masificación tiene su respuesta jurídica en la estandarización de la contratación. La contratación negociada es sustituida por la contratación en masa que exige la pura adhesión. Todo esto es producto de las exigencias del mercado, de la automatización y la racionalización de la economía. La tecnificación también ha venido a cambiar el escenario: los llamados contratos con máquinas automáticas, la facturación por ordenadores, la contratación por Internet, tráfico de ventanillas, etc., exigen urgentes cambios en la doctrina de los contratos.

Como se ha dicho, esta nueva realidad, la de la contratación en masa y de consumo, produce una erosión en la teoría clásica de la contratación y la consiguiente necesidad de elaborar una nueva teoría general que involucre estas nuevas expresiones del mercado y sus correlatos jurídicos; también queda en entredicho, la vigencia de los principios generales que hasta ahora han gobernado la teoría tradicional de los contratos: El pacta sunt servanda, la autonomía de la voluntad, la justicia contractual, etc. En otros términos, la nueva problemática nos plantea acaso, la creación de nuevos principios contractuales y como consecuencia nuevas figuras normativas.

Aun cuando el impacto de la contratación en masa ha sido importante, creemos que el remozamiento de la doctrina contractual viene a forjarse en el surgimiento del Derecho del consumo. En efecto, el Derecho del consumo choca con la visión tradicional de contrato, el contrato no es más un asunto sólo de los particulares. El Estado no puede permanecer indiferente, ausente al reglamento que crean las partes para regular sus relaciones jurídicopatrimoniales. El contrato de consumo se distancia de la contratación clásica, porque mientras que ésta se presume paritaria, aquél presupone una relación asimétrica. En la contratación clásica las partes son libres e iguales, en la contratación de consumo es recurrente la falta de total libertad y la asimetría de las partes. Ambos tipos de contratación son diferentes y como tal tienen disposiciones normativas también diferentes, pero ambas buscan la eficiencia contractual para que ambas partes satisfagan sus pretensiones y tengan garantizado el cumplimiento de lo pactado. 


\section{Contrato de consumo}

Legislativa, jurisprudencial y doctrinariamente está reconocida la contratación de consumo no como un tipo contractual, sino como una modalidad de contratación con caracteres propios. Se trata de transacciones que se realizan en el mercado, que por sus características no pueden ser dejadas simplemente bajo la esfera de las normas contractuales comunes, es decir las normas del Derecho Privado incorporadas en el Código Civil o Código de Comercio, menos aún en el estado en el que se encuentran estas normas, anquilosadas por los años e inmutables a los nuevos fenómenos y la dinámica del mercado creciente; por ello se han incorporado normas especiales que reclaman su aplicación cuando se trata de esta modalidad de contratar.

En contra de la necesidad de la existencia de esta normatividad especial, podría argüirse que en el Derecho común ya existen soluciones al problema de la asimetría informativa entre las partes, motivo por el cual la necesidad de un sistema legal de esta naturaleza deviene en innecesario. De esta manera, figuras como el error, el dolo o el saneamiento por vicios ocultos podrían ser utilizadas por quien se hubiese visto afectado por un problema de información asimétrica entre las partes, en la medida que se vea afectada su manifestación de voluntad.

La existencia de un régimen diferente se justifica plenamente, pues la legislación civil, como hemos visto, ha revelado su impotencia ante estas situaciones. Las razones son varias. En primer lugar, los principios en los que se basa la contratación clásica no se aplican linealmente a la contratación de consumo, la libertad se halla recortada, la igualdad no existe y la manifestación de voluntad no es expresión plena del querer. Adicionalmente, el excesivo carácter burocrático de la jurisdicción civil ordinaria desalienta la posibilidad de denunciar los abusos y disfunciones en la relación de consumo.

\section{3. crisis de la contratación clásica}

Veamos ahora cómo surge la contratación de consumo y cómo afecta a la contratación civil.

El capitalismo en su última etapa exige, debido a la competencia, la reducción de sus costos. Esto lo conduce a la producción en masa de bienes y servicios y la necesidad de una ampliación o ensanchamiento del circuito de los posibles clientes o destinatarios de los bienes y servicios producidos. Diez Picazo (1996) sostiene que el empresario, en el capitalismo avanzado, tiene que llevar a cabo una producción masiva, determinada con la mayor probabilidad posible antes de conocer el número real de los eventuales clientes, a los que es necesario captar a través de fenómenos muy singularizados como el marketing y la publicidad.

El influjo del movimiento civil en defensa del consumidor y el fenómeno de la producción en masa que venían ya desde los años 50, trajo también como consecuencia una anonimización y despersonalización del vendedor y la masificación de los consumidores que no tienen más que aceptar mercadería ofrecida y suscribir contratos de adhesión con cláusulas predispuestas. Esto implica que sistemas jurídicos como el nuestro, inspirados en el clásico Código de Napoleón se consideren en crisis porque el contrato como símbolo y expresión de la autonomía de la voluntad ha perdido vigencia y se atiende hoy al papel que cumple en la sociedad moderna, perdiendo progresivamente el significado de acuerdo de voluntades para 
asumir el papel de un simple acto de sometimiento a una determinada disciplina predispuesta por fuentes extrañas a la voluntad de las partes, provenientes de los poderes públicos o de entes u organismos privados.

No obstante esta realidad que no puede ser negada ni discutida por el Derecho, particularmente creemos que mientras sea posible aún celebrar un contrato interindividual, como por ejemplo una compra venta de casa habitación, se mantendrán vigentes los principios contractuales clásicos que establece el código civil, puesto que no toda adquisición de bienes es de carácter masivo, por lo tanto será la contratación masificada a la que se aplique las disposiciones pro consumidor por tratarse de una contratación de consumo, mientras que en los demás contratos se aplicará las normas del Código Civil.

Obviamente hay posiciones encontradas al respecto, pero creemos que hay que tener en consideración cual es el objeto de la contratación y que tipo de relación está de por medio, o sea si es contratación de consumo o interindividual.

En este aspecto, los instrumentos jurídicos tradicionales también han revelado su insuficiencia, surgiendo la necesidad de crear nuevas expresiones jurídicas más de cara a esta realidad. Para decirlo en una frase, la responsabilidad civil codificada tampoco es apta para regular los daños en las relaciones de consumo, por lo tanto, ha sido preciso crear nuevos instrumentos, hoy expresados en leyes especiales.

Queda claro, por otra parte, que el fenómeno es global; en el Perú acontece sólo un reflejo de lo que sucede en todo el mundo, donde los fenómenos derivados de la problemática del consumidor presiona las normas clásica del Derecho Civil en la búsqueda de nuevas construcciones jurídicas que respondan mejor las situaciones cada vez más originales y novedosas que plantea la sociedad de consumo.

\subsection{Replanteamiento de Autonomía de la voluntad}

El surgimiento en el Derecho privado, a nivel mundial, de una política de protección al consumidor, ha permitido que se pueda hablar, no sin reservas de Derecho del consumo, que en nuestra región tiene como principales expresiones El Código de Protección y Defensa del Consumidor del Brasil, el reciente Código de Protección y Defensa del Consumidor y la Ley de Competencia Desleal del Perú, la Ley de Defensa del Consumidor de Argentina, Ley Federal de Defensa del Consumidor del México, la legislación especial de Colombia, entre otras.

En otras latitudes, como en España y en la Unión Europea el desarrollo ha sido aún mayor, así se ha regulado no sólo la protección al consumidor como norma genérica, sino algunas modalidades contratos en particular como: contratos celebrados fuera de establecimientos mercantiles, la venta ambulante, venta en mercadillos y mercados ocasionales, crédito al consumo, contrato de viaje combinado, etc.; y desde luego no podemos olvidar la reciente norma sobre cláusulas generales de contratación. 


\subsection{Carácter vinculante de las normas contractuales dispositivas}

Frente a esta problemática el Profesor Federico de Castro y Bravo ha planteado el carácter vinculante de las normas contractuales dispositivas si las partes no las han derogado justificadamente para su reglamento contractual.

Las reglas dispositivas no han sido puestas en las leyes a modo de modelo o ejemplo, que se deja al arbitrio de los contratantes el seguirlas o no seguirlas. En general, han sido recogidas como consecuencias naturales o típicas de cada clase de contrato. Responden a lo que se ha estimado normal según los intereses en juego, de acuerdo con el buen sentido, de lo tradicional y los dictados de la equidad respecto a la debida equivalencia de las respectivas obligaciones.

\subsection{Resolución unilateral en el contrato de consumo}

La inadecuación de la tradicional teoría de la justicia contractual, basada en la autonomía de la voluntad, ha creado la necesidad de atender al contenido de los contratos, así como todo su proceso de formación, con el propósito de evitar que la situación de debilidad de los consumidores los haga víctimas de abusos.

Esto se hace aún más evidente cuando constatamos que nuestro Derecho en diversos casos recoge normas que parten de la presunción de debilidad del consumidor y la necesidad de protección que tiene. Es el caso del artículo 1 del Código de Protección y Defensa del Consumidor del Perú, se permite el prepago de obligaciones dinerarias con la correspondiente liquidación de intereses. Esta norma sería eventualmente inadmisible en el Derecho Civil clásico. La regla en el Derecho civil es que los contratos se celebran para ser cumplidos; sin embargo, en el propio Código Civil Peruano, por ejemplo existen casos excepcionales en que se permite la resolución unilateral del contrato, tales los casos de los arts. 1769 y 1768 que permiten al Locador y al Comitente resolver unilateralmente el contrato de Locación u obra respectivamente, pero con las limitaciones señaladas en dichos artículos.

\section{Cambios que genera el derecho del consumidor en el derecho civil}

El impacto que el Derecho del Consumidor ha tenido en el Derecho Civil ha sido de grandes proporciones, por lo que es preciso determinar la manera concreta como se ha manifestado esta influencia; algunas de estas normas inciden directa o indirectamente en el Derecho Civil, afectando con mayor o menos intensidad, según los casos, a diferentes aspectos de la teoría general del contrato.

Vega Mere (1996) en relación a la legislación peruana, considera que en relación a la juridificación de la fase pre contractual, es necesario añadir el tema de la llamada oferta al consumidor que ha creado nuestro Derecho del Consumo. En efecto, en el Perú, hasta antes de la Ley de Protección al Consumidor, la oferta era regulada básicamente por el Código Civil. Así, el Código Civil Peruano, había recogido varias clases de ofertas, tales como ofertas alternativas (artículo 1371), ofertas cruzadas (artículo 1378), contra oferta (artículo 1376), oferta al público (artículo 1388) Esta última ha sido legislada como una invitación a ofrecer y, por tanto, carece de carácter vinculante, es decir, no obliga al proponente, sino que éste será el destinatario de las ofertas que le lancen. 
Sin embargo, las legislaciones de protección del consumidor como el artículo 46 del Código de Protección y Defensa del Consumidor Peruano, establece el carácter obligatorio de toda oferta pública o privada que se lance al consumidor. De esta manera, si el proveedor lanza una publicidad por medio de la cual promociona sus productos indicando las características, ventajas y precio de aquellos se entenderá que se trata de una oferta al consumidor y por consiguiente será exigible por éste. Como se observa, el tratamiento normativo que se le da a la oferta -incluida la oferta al público- se aparta de lo prescrito por el código, creando lo que en nuestra doctrina se ha llamado oferta al consumidor.

Todo esto nos lleva a considerar a la publicidad como oferta, en el derecho del consumidor, pero además de su importancia en la formación del contrato, también la tiene en la determinación de su contenido, pues el proveedor queda vinculado por el contenido de su anuncio -oferta- cuando contrata con el consumidor, aunque en el contrato se silencien los aspectos enunciados.

De esta manera, las legislaciones de protección del consumidor y en particular las normas del Código de Protección y Defensa del Consumidor Peruano ha creado un nuevo tipo de oferta, la llamada oferta al consumidor, que se aparta de los alcances de la oferta regulada por el Código Civil; las características propias de la oferta al consumidor son las siguientes:

a) Puede o no ser recepticia, es decir, puede estar dirigida a una persona determinada o ser dirigida al mercado.

b) Siempre es vinculante, a diferencia de la oferta al público regulada en el Código Civil

c) Sus alcances rebasan el mero documento contractual.

d) En caso de ofertas promocionales, el deber de información del proveedor es agravado al punto de exigirle precisiones sobre la duración de la promoción y unidades disponibles.

A todo esto se añade que en otros países, en los que se encuentra más avanzado el Derecho del Consumidor, incluso se ha llegado a derogar en ciertos casos el principio de obligatoriedad de los contratos. Es el caso de varios países de la Unión Europea y en especial España. Nos referimos concretamente a la concesión de un plazo para la revocación del contrato, sobre todo aquellos celebrados fuera de establecimientos mercantiles, muy de moda en mercados como el de hoy donde la dinámica mercantil profusa.

Como sucede con el artículo 5 de la Ley sobre contratos celebrados fuera de los establecimientos mercantiles de España, que establece Ejercicio del derecho de revocación: "El consumidor podrá revocar su declaración de voluntad sin necesidad de alegar causa alguna, hasta pasados siete días contados desde la recepción. Para determinar la observancia del plazo, se tendrá en cuenta la fecha de emisión de la declaración de revocación".

\subsection{La Información en la Contratación Civil}

Otra situación que se produce como consecuencia de la aparición del contrato de consumo, es la relativa al derecho de información de los contratantes. En la doctrina que sirvió de fundamento para la elaboración de los códigos civiles occidentales -incluido el nuestro- corresponde a cada contratante adquirir la información sobre los alcances de las obligaciones, prestaciones y objeto de éstas que generará el contrato. 
No obstante, en vista de la asimetría informativa existente en las relaciones de consumo, en éstas es una obligación de una de las partes -el proveedor- proporcionar información. Por ello, la necesidad de la imposición de un deber genérico de información por parte del proveedor, que subsane el déficit informativo del consumidor y permita que exprese su consentimiento suficientemente informado.

Las legislaciones de consumidor tienen esta tendencia, así se comprueba de la lectura del artículo 2 del Código de protección y Defensa del Consumidor del Perú, que señala taxativamente que el proveedor está obligado a consignar en formar veraz, suficiente, apropiada muy fácilmente accesible al consumidor o usuario, la información sobre los productos y servicios ofertados. Tratándose de productos destinados a la alimentación y la salud de las personas, esta obligación se extiende a informar sobre sus ingredientes y componentes.

Está prohibida toda información o presentación que induzca al consumidor a error respecto a la naturaleza, origen, modo de fabricación, componentes, usos, volumen, peso, medida, precios, forma de empleo, características, propiedades, idoneidad, cantidad, calidad o cualquier otro dato de los productos o servicios ofrecidos.

Podemos concluir lo siguiente:

El consumidor es la parte débil en el contrato de consumo; su debilidad es estructural, es decir, responde a su ubicación en el mercado y a la lógica de éste. Esta debilidad se funda en un déficit de negociación, déficit de reflexión y sobre todo déficit de información.

Cabe precisar también que cualquier contratante que tenga un desconocimiento de aquello que contrata, es decir que tenga un déficit de información en su relación contractual es también un contratante débil en la medida que queda expuesto a lo que la contraparte exprese por ser quien tiene la información.

Los principios que sirvieron para edificar la teoría clásica de la contratación civil se revelan insuficientes cuando se advierte que las figuras jurídicas a las que dieron origen, son ineficientes cuando pretende regular el contrato de consumo.

Caen o cuando menos se relativizan los siguientes dogmas:

a) El de la irrelevancia de la fase precontractual.

b) El de la irrelevancia de la desinformación y de toda coacción que no integre ninguno de los supuestos de los vicios del consentimiento

c) El del pacta sunt servanda.

d) El de neutralidad del Derecho frente al contrato; ya no puede afirmarse que el Derecho se preocupa de las reglas de juego, pero no del juego.

e) El de la justicia contractual objetiva.

Se supera el principio de la relatividad del contrato, desde que no sólo el consumidor contratante le puede exigir al proveedor el cumplimiento de sus obligaciones, sino también quien, aunque no contratando con él, consuma el bien o utilice el servicio.

Surgen figuras legales que se apartan de la contratación clásica: 
a) Oferta al consumidor.

b) Revocación de ciertos contratos de consumo (esta figura aún no ha sido recogida en el Perú).

c) Facultad del consumidor de resolver unilateral e inmotivadamente el contrato de crédito al consumidor.

d) Interpretación a favor del consumidor en los contratos de consumo.

e) Principio Pro Consumidor.

Por último, consideramos indispensable que el Código Civil regule, aunque de modo genérico, la contratación de consumo.

\subsection{Compra Venta de Inmuebles en construcción como bienes futuros}

Un hecho que se viene observando es la compra venta de inmuebles (casas y departamentos) en construcción como bienes futuros y el problema legal se presenta porque las empresas constructoras ofrecen un inmueble con un metraje determinado generalmente alto para llamar la atención y promover la venta, luego al entregar el inmueble ya terminado, se verifica que faltan metros y ante el reclamo de los compradores se ajusta el precio, sobre la base de que se trata de venta de bienes futuros y expresan que no hay problema alguno, toda vez que este tema está regulado en el Código Civil .

Particularmente, creemos que en este caso hay una falta contra los derechos del consumidor porque se promociona un inmueble con un metraje determinado, con una publicidad engañosa y luego se vulneran las expectativas de los compradores entregándoles un departamento o una casa con otro metraje, obviamente menor y aunque se ajuste el precio, la falta ya se produjo, ya se afectaron sus intereses y sus expectativas, más aún si los consumidores son generalmente gente de clase media que por primera vez compra un inmueble con mucha esperanza gracias al boom de los préstamos hipotecarios y de programas sociales de construcción de viviendas populares llevados a cabo en las grandes ciudades y conos urbanos de las capitales latinoamericanas como por ejemplo los programas sociales de Trecho Propio y Mi Vivienda promovidos por el Estado Peruano durante el gobierno del Presidente Alejandro Toledo (2001-2006) y continuados por el Presidente Alan García Pérez (2006-20011) como estrategias políticas y de gestión pública para paliar el problema de viviendas populares .

El Tribunal de Defensa de la Competencia del Instituto Nacional de Defensa de la Competencia y Protección de la Propiedad Intelectual del Perú (INDECOPI) ya se ha pronunciado al respecto a través de una interesante jurisprudencia administrativa que creemos es aleccionadora en la doctrina del Derecho Privado y en particular en el Derecho Civil y lo que creemos es que no se trata propiamente de una venta de bien futuro conforme lo expresado por las legislaciones civiles como es el caso del Código Civil Peruano, sino que estamos frente a la presencia de un contrato de obra de ejecución diferida donde la prestación consiste en la obligación de entregar un inmueble de determinadas características. En efecto, consideramos que el Código Civil Peruano de base romanista, al hablar a bienes futuros se refiere a aquellos cuya materialidad depende obviamente de la futuridad, es decir de un evento incierto que puede eventualmente afectar las características del bien futuro que una de las partes se obliga a entregar, como por ejemplo las cosechas o las crías del ganado que pueden verse afectadas por las lluvias o la sequía o el alimento, etc. y en estos caos es obvio que el precio debe ajustarse a las características reales de aquello que se entrega, lo cual tiene lógica. 
Por otra parte, el Código Civil al hablar de ajustes en inmuebles estaba pensado en predios rurales, donde es posible que por cuestiones geográficas, o por la configuración topográfica del suelo, se afecte el área previamente acordada entre comprador y vendedor, pero de ninguna manera puede alegarse este tipo de situaciones futuras e inciertas en la venta de una unidad inmobiliaria en un edificio en construcción o en una casa previamente delineada y trazada en un plano con mediciones precisas. En efecto, hoy en la industria de la construcción es posible diseñar y proyectar como quedará finalmente la obra, incluso con la ayuda de la informática, de manera tal que el trazado, la planimetría de distribución y de diseño de la obra en construcción nos llevan a un resultado preciso y determinado de manera que no se puede alegar la falta de metros cuadrados, no se puede hablar de mermas, eso es inadmisible.

Es posible que pueda haber algunas diferencias mínimas que incluso el propio Reglamento Nacional de Construcciones acepta, pero de ninguna manera se puede hablar de un déficit de $5,10,20$ o 30 metros cuadrados. Por lo expuesto, consideramos que se puede hablar con más propiedad y desde el punto de vista de la teoría del contrato-realidad, que estamos ante la figura de un contrato de obra de ejecución diferida, toda vez que la parte interesada, es decir el comprador participa también activamente en la obra dando algunas indicaciones y precisiones para el resultado final de la obra.

Este es un tema de gran trascendencia social que pone de manifiesto nuevamente la complementariedad para no hablar de influencia de las normas del Derecho del Consumidor sobre el Derecho Civil, por ello creemos que en este caso no se aplica la norma contenida en el Código Civil sino que ante una petición o un reclamo de esta naturaleza, éste tiene necesariamente que ser enfocado desde la perspectiva de la Ley de Protección del Consumidor, caso contrario estaríamos desatendiendo a un grueso sector de ciudadanos consumidores que se ven afectados en su esfera económica, por una publicidad engañosa que ha mediatizado su decisión de consumo llevándolos a comprar la casa de sus sueños con un metraje menor al que pensaban., siendo precisamente este sector social los más vulnerables en el mercado, situación que no puede ser negada ni desconocida.

El Indecopi se ha pronunciado al respecto y aunque no ha establecido que se trata de contratos de ejecución de obra de ejecución diferida, si ha establecido que no se puede aplicar a este tipo de contratos la teoría de la venta de bienes futuros, haciendo una interpretación normativa que merece ser destacada, señalando incluso en la Resolución No 1223-2006 TDC/INDECOPI que no se trata de venta en la modalidad ad corpus, sino que se trata de un inmueble con ciertas características y medidas, las cuales se ceñían de acuerdo a lo pactado.

Asimismo la Sala de Defensa de la Competencia ha considerado como falta de Idoneidad la venta de inmuebles en proyectos habitacionales sin haber efectuado las diligencias administrativas de zonificación para áreas de centros educativos, áreas recreacionales, de jardines etc., Resolución No 203-2005 TDC/INDECOPI. También se ha considerado falta de idoneidad la venta de inmuebles con problemas de fugas de agua por descascaramientos en paredes, manchas en las paredes, etc. Resolución No 0342-2006 TDC/INDECOPI.

Otros temas en los que igualmente la sala ha establecido que se trata de falta de idoneidad en materia de construcción es la demora en la fecha de entrega, malas instalaciones 
eléctricas y/o sanitarias, rajaduras, grietas en las paredes, mala instalación de parquet y pisos cerámicos, etc.

\section{Derecho del consumidor y el régimen jurídico de las cláusulas generales de contratación y del contrato por adhesión}

Antes se creía que hablar de un sistema de protección del consumidor implicaba necesariamente conjugar bajo un mismo marco normativo, es decir unificado, las reglas que establecieran los derechos de los consumidores, las obligaciones de los proveedores y el control de las modernas técnicas de contratación: entiéndase cláusulas generales de contratación y los contratos por adhesión.

En Europa, existe por ejemplo la Directiva del Consejo de la Comunidad Económica Europea del 5 de Abril de 1993, sobre las cláusulas abusivas en los contratos estipulados con los consumidores, incorporadas a la legislación interna de algunos países como es el caso de Italia en su Código Civil.

Consideramos que existen vinculaciones entre ambos, pero son diferentes. El Derecho Del Consumidor tiende a proteger a los destinatarios finales de los bienes y servicios de los efectos dañinos de la asimetría informativa existente en el mercado; en cambio el objeto de las cláusulas generales de contratación es agilizar el tráfico comercial, es decir viabilizar mejor la comercialización de los bienes y servicios, reduciendo los costos de transacción y las discusiones o tratativas contractuales, dada la identidad de los productos colocados en el mercado.

El hecho de que exista una relación entre ambos temas, no quiere decir que las disposiciones del Código Civil sobre dichas modalidades de contratación masiva tienen una inspiración única y exclusiva en el principio pro consumidor. Según Vega Mere (1996) la figura del consumidor no gravitó en la regimentación de las cláusulas generales de contratación, posiblemente lo determinante fue la idea de tutelar a la parte débil, entendiendo a ésta como aquélla que no participaba en la predisposición del clausulado.

Existe una confusión derivada quizás del hecho de que antes de la vigencia del Código Protección y Defensa del Consumidor del Perú, el Código Civil Peruano de 1984, introdujo diversos niveles de control al contrato por adhesión y a las cláusulas generales de contratación al advertir que en el mercado en aquel entonces, los proveedores de bienes y servicios contaban con el poder suficiente para imponer sus condiciones a los usuarios y en tal sentido decidió darles protección haciendo uso de la fórmula "favor debitoris", identificando a lo que hoy entendemos como consumidor con la parte deudora de la relación obligatoria. El favor debitoris era, asimismo, una opción del legislador, al estimar que la parte débil de las relaciones obligatorias masivas era aquella que no predisponía o prerredactaba las condiciones generales de contratación o el contrato por adhesión.

Por lo tanto el control relativo al contrato por adhesión y a las cláusulas generales de contratación se debió a la aplicación de aquella orientación y no a la figura del consumidor como algunos autores creen.

El derecho del consumidor ya se venía reclamando por parte de la doctrina, y nace con la puesta en vigencia de diversas legislaciones promotoras y defensoras de los Derechos del Consumidor en la región, como El Código de Protección y Defensa del Consumidor del 
Brasil, el reciente Código de Protección y Defensa del Consumidor y la Ley de Competencia Desleal del Perú, la Ley de Defensa del Consumidor de Argentina, Ley Federal de Defensa del Consumidor del México, la legislación especial de Colombia, entre otras, gestadas todas en la década del noventa, hasta dar paso ahora a una disciplina jurídica autónoma, con su propio contenido, sus propias reglas de interpretación, sus principios, criterios y líneas de pensamiento moderna en materia de contratación de consumo que van más allá del clásico Derecho Civil y que están destinadas a generar transparencia en las relaciones de mercado entre proveedores y consumidores para generar eficiencia contractual y por ende respetar los derechos de los consumidores.

El maestro Manuel de la Puente y Lavalle (2000) señala que al momento de su redacción las cláusulas generales de contratación tienen, por definición, carácter abstracto, es decir que al redactarlas no se toma en consideración la personalidad de las futuras contrapartes en los contratos particulares que se van a celebrar en base a ellas, por lo cual dichas cláusulas no pueden ser consideradas como una oferta contractual, ya que ésta es una declaración recepticia, o sea está destinada a ser reconocida por un destinatario determinado.

De la Puente y Lavalle (2000, p.48) en torno a las clausulas generales de contratación expresa:

"Se ha elaborado mucho, y quizá irreflexivamente he participado en esa línea de pensamiento, respecto a que la regulación legal de las cláusulas generales de contratación tienen por objeto fundamental proteger al contratante débil. Es cierto que esta protección ha jugado un rol importante, porque generalmente el cliente o consumidor se encuentra en una situación de inferioridad con relación al empresario predisponente de las cláusulas, lo que ha llevado a pensar que, a semejanza del contrato por adhesión, existe en la contratación a base de dichas cláusulas una debilidad del consentimiento asimilable a un vicio de la voluntad. Se ha dicho no sin razón que el aparato publicitario de los suministradores de bienes y servicios ha creado en los consumidores un complejo de inferioridad, un estado psicológico de dependencia, que los lleva a aceptar sumisamente las cláusulas generales de contratación".

El tráfico moderno ha puesto de manifiesto algo que quizá había escapado inicialmente a la perspicacia del legislador, preocupado por garantizar el equilibrio contractual. Para Mirabelli (1980) lo cierto es que no se trata de un problema de protección al cliente o consumidor sino de atención a las necesidades impostergables de dicho tráfico, que requieren de un sistema legal que permita concertar simultáneamente una gran cantidad de negocios con gentes que se encuentran en similares condiciones en lo que respecta a la provisión masiva de bienes y servicios.

En este contexto se entiende que las cláusulas generales de contratación para que puedan cumplir eficientemente su rol de permitir la celeridad en el comercio masivo de bienes y servicios, necesitan de una especial aptitud para facilitar y promover la contratación. Ello es posible otorgándoles determinadas características que giran sobre la base de tres elementos: Predisposición, Generalidad e Inmutabilidad. 
Manuel de la Puente y Lavalle (2000, p.60) también ha expresado al respecto que:

"Los consumidores no son necesariamente los únicos que contratan sobre la base de dichas condiciones generales. Si lo hacen nadie duda que en ese caso la reglamentación de las cláusulas generales de contratación tendrá algunos puntos de contacto con el Derecho de los Consumidores". Coincidimos con De la Puente y Lavalle en el sentido de que en el sistema peruano y creo que en general en todos los sistemas jurídicos que tiene como base del derecho Privado un Código Civil, el rol de las cláusulas generales de contratación y del contrato de adhesión, es fundamentalmente permitir la contratación masiva para la provisión de bienes y servicios, jugando un papel secundario, aunque no menos efectivo, la protección de los intereses de las partes, especialmente los del consumidor, no porque no sean importantes sino porque estas sujetos a otro tipo de regulación jurídica”.

\section{El contratante débil}

La figura del consumidor como el contratante débil es un tema que también ha generado varias posiciones al respecto. Antes y aún después de considerar al consumidor como destinatario final de bienes y servicios se asumió que éste era en el mercado y en toda relación contractual de consumo la parte débil. Sin embargo la idea de la parte débil en una relación responde a una circunstancia histórica cuando existían abusos como consecuencia del capitalismo que desconoció algunos postulados de la libre competencia y que motivó la intervención del Estado en esta materia.

Una inicial concepción inadecuada de la noción de parte débil condujo a que se le identificara así al deudor de la relación obligatoria en la configuración de un contrato, lo cual se evidencia con las normas que consagran la opción del "favor debitoris". A esta orientación responde el estudio de Arias Schereiber (1988).

Ripert (1951) establece que esta opción legislativa no siempre responde a la verdad de los hechos porque también el acreedor de una relación obligatoria puede ser considerado como parte débil, en consecuencia esta noción de contratante débil se fue abriendo para dar paso a otra tendencia para favorecer a la parte privada de poder económico para diseñar el esquema negocial bajo la égida del principio "favor debilis".

Cuando surgen los consumidores como protagonistas del mercado, la doctrina y la legislación tuvieron la tendencia de considerar al consumidor como parte débil invocando por error, algunos el principio favor debitoris no obstante tuvo mayor acogida el principio "favor de bilis" establecido por Ripert.

En otras palabras la parte débil de un contrato es aquella que no tiene el poder suficiente para establecer el esquema contractual o, que tiene un déficit considerable de información respecto del objeto del contrato y que lo pone en una situación de desventaja frente a la otra parte. De manera que la noción de parte débil no solamente está presente en los contratos de consumo masivo o en la contratación estandarizada o por adhesión, sino también puede estar presente en una relación contractual Interindividual e inclusive una empresa puede en una determinada relación contractual tener el carácter de parte débil si es que desconociera ciertos aspectos que posee el otro contratante. 
En consecuencia la noción de parte débil no necesariamente está ligada directamente a la dimensión económica o patrimonial de un contratante sino a su situación en determinado contrato.

Es obvio que en el consumo masivo el consumidor no siempre tiene el conocimiento apropiado respecto de los bienes y servicios que consume y no está adecuadamente informado y generalmente se le ve en la disyuntiva de adquirir o no el producto sin ninguna posibilidad de negociación o reflexión y ante este déficit informativo que la doctrina moderna llama asimetría informativa, evidentemente está en una situación de "contratante débil" frente al proveedor que goza de una situación ventajosa en cuanto a información sobre los bienes y servicios que ofrece y las condiciones contractuales que generalmente él preestablece.

Para solucionar esta situación las legislaciones de protección y defensa de los consumidores insisten reiteradamente en el deber de los proveedores de informar y de informar adecuadamente a los consumidores y esto no debe ser interpretado como una carga sino como el principio "favor debilis" que recoge dichas normas.

Por lo general se sostiene que el consumidor es la parte débil porque carece en principio, de información así como también de capacidad para negociar el contrato debido a diferencias económicas con la otra parte contratante. El deber de información aun cuando no se encontrase debidamente legislado es una de las reglas de juego del mercado conjuntamente con el precio y las garantías y en efecto nadie comprará nada si no recibe información o si no sabe absolutamente nada de aquello que va a adquirir.

También se sostiene que el consumidor tiene una debilidad estructural en el mercado o que es la parte débil en los contratos por adhesión o en los celebrados de acuerdo a cláusulas generales de contratación por no participar en su predisposición, ello es evidente por eso el Código Civil Peruano de 1984 estableció una serie de normas a fin de limitar a los contratos por adhesión y a las cláusulas generales de contratación. No obstante, no siempre el que suscribe este tipo de contratos es un consumidor, puede también un proveedor, sea empresa o no aceptar las condiciones establecidas previamente por otro empresario. Lo mismo puede decirse de las personas jurídicas que adquieren bienes o servicios como consumidores.

Coincidimos con De la Puente y Lavalle (1995, p.15) cuando expresa que:

Si pueden ser consumidores tanto las personas físicas como las jurídicas, no es extraño que un consumidor no sea parte débil de la negociación contractual, tanto más si el proveedor no ostenta el monopolio del bien o servicio. En efecto, el consumidor que puede satisfacer su necesidad de un cierto bien o servicio de varios proveedores, no se ve compelido a celebrar el contrato de adquisición con un determinado proveedor, sino, que puede recurrir indistintamente a varios de ellos, con lo cual el proveedor elegido por el consumidor no tiene la condición de parte fuerte en la negociación contractual. Además, consumidor y no consumidor, sólo pueden ser parte débil en la negociación contractual si se encuentran en estado de necesidad respecto de la provisión de un bien y servicio y consideran que únicamente a través de un determinado contrato a celebrarse, con persona cierta pueden satisfacer tal necesidad. 
Las normas que tutelan el derecho del consumidor no parten de esta presunta debilidad y tal como expresa De la Puente y Lavalle, la protección de los derechos del consumidor no es necesariamente contra los actos del proveedor, sino que está orientada en realidad, a garantizar que los bienes y servicios que adquiera el consumidor sean idóneos para su consumo final por éste.

Cabe, por tanto, afirmar que no debe identificarse la condición de consumidor o usuario con la de parte débil. Es, en rigor, la parte que carece o puede carecer de información y que no siempre podrá negociar las condiciones de comercialización, cuando no tenga ninguna otra alternativa de elección.

El consumidor es un contratante ocasional que acude al mercado no como profesional, sino diríamos como amateur que adquiere bienes y servicios no para reingresarlos al mercado sino para su propio consumo o el de su entorno familiar o social, por lo tanto el concepto de consumidor como contratante débil no es una noción individual, sino una categoría; es decir la cualidad o condición con la que se acude a celebrar un contrato.

Gutiérrez Camacho (2004) sostiene que se es contratante débil principalmente porque se adolece de un déficit de información y de capacidad para procesar toda la información existente en el mercado, lo que a su vez genera una desigualdad manifiesta en la negociación cuando la hay y en la conclusión y ejecución del contrato.

En conclusión podemos establecer que el Derecho del Consumidor ha hecho una construcción empírica especializada sobre la base las instituciones que en su momento creo el Derecho Civil y que hoy ya no son aplicables para determinado tipo de contratación, como es la contratación de consumo que hoy desborda inevitablemente los alcances normativos que estableció el Derecho Civil. Por ello es preciso señalar que no existe un desplazamiento del Derecho Civil por parte del Derecho del Consumidor, sino que existe una relación de complemento y desarrollo del Derecho del Consumidor respecto de los efectos jurídicos que traen aparejados los modernos mecanismos de contratación de consumo.

\section{Responsabilidad civil en el ámbito del derecho del consumidor}

En el caso peruano, el Código de Protección y Defensa del Consumidor, estipula una serie de normas que de una u otra manera establecen disposiciones de responsabilidad civil por los daños que el empresario proveedor cause a los consumidores en la comercialización de sus bienes y servicios. En efecto del artículo 100 pueden eventualmente derivarse responsabilidad civil por haber generado falsas expectativas respecto a la promoción u oferta publicitada de determinado bien o servicio o por los daños ocasionados por el incumplimiento de la oferta publicitaria; el artículo 30 obliga a reponer el producto devolver la cantidad pagada en exceso cuando exista discrepancia entre la cantidad supuestamente vendida y la cantidad efectivamente entregada; el mismo razonamiento tienen los artículos $101,102,103$

La norma ha efectuado un tratamiento riguroso del tema de la responsabilidad civil en su título "De las Responsabilidades frente a los Consumidores", y en este sentido la ley aborda la responsabilidad civil por productos defectuosos estableciendo que el proveedor es responsable de los daños y perjuicios causados a la integridad física de los consumidores o a sus bienes por los defectos de sus productos y se considera que un producto es defectuoso cuando no ofrece la seguridad a que las personas tienen derecho, tomando en consideración 
todas las circunstancias, como el diseño del producto; la manera como ha sido puesto en el mercado, su apariencia, su marca, la publicidad referida a la misma o el empleo de advertencias o instrucciones; el uso previsible del producto; los materiales, el contenido y la condición del producto, entre otros.

La ley establece también el carácter omnicomprensivo de la responsabilidad civil y en tal sentido expresa que la indemnización comprende todas las consecuencias causadas por el defecto, incluyendo el lucro cesante, el daño a la persona y el daño moral y que la responsabilidad de los diversos proveedores de un producto es solidaria, sin perjuicio obviamente de que cada proveedor tiene el derecho de repetir contra aquel que le suministró el producto defectuoso causante de los daños; de manera que la omisión de información por parte del proveedor, en especial de las instrucciones o advertencias, determinan responsabilidad civil en tanto que el producto defectuoso se constituye en la causa adecuada de los daños que eventualmente sufre el consumidor, en cuyo caso no es necesario analizar la culpa del proveedor, quien debe responder objetivamente por el daño causado.

La Autoridad Nacional de Protección del Consumidor en el Perú (Indecopi) a través de su Comisión de Protección del Consumidor y de su actual Sala de Protección del Consumidor del Tribunal del Indecopi, no tenía facultades para pronunciarse sobre la pretensión de medidas correctivas solicitadas por un consumidor afectado, porque se entendía que estas tenían un carácter indemnizatorio y esta facultad es propia del poder Judicial. Sin embargo la Ley 27311del año 2003 otorgó a la Comisión la facultad de ordenar, entre otras medidas la reposición y reparación de productos, la devolución de la contraprestación pagada por el consumidor o cualquier otra medida que tenga por objeto el reponer el estado de las cosas hasta antes de la producción del daño. Algunos autores consideran a estas medidas como un resarcimiento del daño dadas las expectativas económicas del consumidor y las consideran como eventuales indemnizaciones por especie para resarcir el daño emergente y propugnan una corriente de opinión para otorgarles este carácter; sin embargo creemos que en el actual contexto normativo, las medidas correctivas no tienen ese carácter, porque las indemnizaciones responden otros criterios y solo pueden ser fijadas por mandato judicial, caso contrario deberá modificarse toda la dogmática civil sobre la responsabilidad para trasladar este tema a los órganos administrativos.

Pero cuál es la naturaleza de la responsabilidad civil que contempla la Ley de Protección del Consumidor? Al respecto el artículo 101 del Código en referencia señala que los proveedores son objetivamente responsables por infringir las disposiciones contenidas en la ley y que los proveedores infractores podrán ser sancionados con una amonestación o multa de hasta 500 Unidades Impositivas Tributarias (US 500,000 aproximadamente), sin perjuicio de las medidas correctivas que correspondan para revertir los efectos que las conductas infractoras hubieran ocasionado o para evitar que éstas se produzcan nuevamente en el futuro. El debate es si se trata de responsabilidad civil objetiva o de responsabilidad administrativa. En nuestra opinión la ley contempla un principio de responsabilidad objetiva y en tal sentido un proveedor infractor responderá administrativamente por la infracción las normas de protección del consumidor, pero a su vez responderá también objetivamente si a consecuencia de la infracción administrativa ha causado daños al consumidor en cualquiera de sus dimensiones, es decir daños materiales o patrimoniales y daños personales.

El Código de Protección y Defensa del Consumidor del Perú, en esta materia es innovadora y marca la pauta en las legislaciones de la región y en ese sentido está a la vanguardia, al estatuir normas tanto de responsabilidad civil contractual, como 
extracontractual y en el caso de productos defectuosos la responsabilidad extracontractual permite dirigirse contra el comerciante o distribuidor, el proveedor, el fabricante $\mathrm{o}$ importador. No obstante creemos que la responsabilidad civil es una sola, dado que el denominador común de ambos tipos de responsabilidad estriba en la antijuridicidad, la obligación legal de indemnizar los daños, la relación de causalidad y los factores de atribución, con diferencias de matiz en su regulación legal. Para Taboada Córdova (2000) la actual regulación del Código Civil peruano no es impedimento para estudiar el sistema de responsabilidad civil desde una óptica unitaria, en la medida en que se respeten las diferencias de orden legal existentes.

El artículo 100 de la El Código de Protección y Defensa del Consumidor del Perú es una norma especial, de aplicación a las relaciones de consumo que establece la responsabilidad civil por productos defectuosos en tanto que los productos no ofrezcan las garantías de seguridad y pongan en riesgo la integridad física del consumidor por falta de información sobre instrucciones de uso o advertencias, lo que se relaciona con el artículo 9 de la ley que señala que los productos puestos a disposición del consumidor no deben conllevar riesgo injustificado o no advertido para su salud o seguridad la de sus bienes, agregando que los riesgos previsibles deben advertirse, así como señalarse el correcto modo de utilización del producto. Es decir, si el producto conlleva un riesgo y no se informa, éste es defectuoso, si el producto tiene determinada forma de uso y no se informa, éste es defectuoso porque se torna inseguro, he aquí donde radica el acto antijurídico como uno de los elementos de la responsabilidad civil.

La responsabilidad es objetiva en tanto que no se requiere demostrar la culpa del proveedor, sino solamente el riesgo creado como factor atributivo de la responsabilidad civil, en virtud del cual se atribuye el daño al proveedor que oferta los productos en el mercado y que potencialmente pueden causar daño por deficiencias de información, uso inadecuado o falta de advertencias, prescindiendo de la subjetividad del agente, centrando el debate en la reparación del daño causado.

Probado el defecto de información y el nexo causal, responde el proveedor. La relación causal debe ser de causa adecuada es decir de una conducta que sea capaz de producir el daño, donde entran en juego factores como la naturaleza del defecto, las instrucciones o advertencias, la intensidad del riesgo creado, la previsibilidad del uso inadecuado, et tipo de lenguaje empleado, etc. El consumidor debe probar que el daño sufrido es a consecuencia del defecto y que hay un nexo causal entre el defecto y los daños, por lo que se debe demostrar que si el defecto no hubiera existido, el daño no se hubiera producido, porque la causalidad adecuada supone que el daño es resultado esperado en circunstancias normales del defecto, es decir que el defecto es idóneo para producir daños.

Lo importante en esta materia es que las normas sobre responsabilidad civil por productos defectuosos contenida en la ley, sea interpretada en armonía con las demás disposiciones sobre protección del consumidor, de la mano del trabajo de aplicación legal de los órganos encargados de resolver los conflictos de consumo, los que deberán atender a desincentivar la producción de daños derivados de productos defectuosos en el mercado, a través de resoluciones que se ajusten a la ley y que tiendan a crear conciencia de cultura de consumo en el país. En 1916 la Corte de Aplicaciones de New York estableció el precedente de Responsabilidad Civil por productos defectuosos en el célebre caso Brow vs Buick Motor Company. 
El incumplimiento de las disposiciones legales establecidas al respecto en la normas de consumidor determina la responsabilidad administrativa del proveedor, sin embargo para que el sistema de protección del consumidor funcione adecuadamente y pueda ser eficiente y eficaz es necesario no solo la aplicación de sanciones administrativas a cargo de las autoridades como en el caso del Perú, el Indecopi, sino también de normas de responsabilidad civil a cargo del Poder Judicial y que otorguen indemnizaciones para reparar de manera integral los daños y perjuicios sufridos por los consumidores a consecuencia de la oferta de productos y servicios defectuosos, de manera que la tutela jurídica del consumidor no solo quede en la esfera del órgano administrativo, sino que también se traslade al ámbito judicial donde un trabajo idóneo de los jueces en esta materia sin duda complementaría el sistema de protección.

Existe una falta de aplicación por parte de los órganos jurisdiccionales peruanos del artículo 100 del Código de Protección y Defensa del Consumidor, sobre responsabilidad civil por productos defectuosos, toda vez que los jueces a pesar de ser esta norma idónea y especializada, prefieren aplicar las regulaciones contenidas en el Código Civil, generando a veces debates inocuos sobre el tema, afectando los derechos de los consumidores, quienes a veces paradójicamente han obtenido ya una resolución favorable en la vía administrativa.

Al respecto, no obstante la existencia de un régimen especial de responsabilidad del productor como el que contempla el artículo 100 del Código de Protección y Defensa del Consumidor, éste no ha tenido aplicación hasta el momento por parte de la jurisprudencia peruana, la que más bien, ha continuado aplicando a los poquísimos casos sobre la materia la disciplina general de la responsabilidad civil. Woolcoot Oyague (2001) sostiene que resulta palmario que los casos de responsabilidad del proveedor por productos defectuosos son propios de economías desarrolladas, lo que explicaría la escasa aplicación de la normativa en el Perú.

La jurisprudencia administrativa del Tribunal del Indecopi en el Perú, revela que existen muchos casos que involucran daños causados a los consumidores y que deberían ser objeto de procesos por responsabilidad civil, sin embargo la realidad nos demuestra que los consumidores no tienen incentivos para demandar judicialmente indemnizaciones por los daños sufridos; quizás porque no saben defender sus derechos, por los altos costos procesales, por la lentitud de los procesos, por el difícil acceso a los órganos jurisdiccionales, etc. Esto explica por qué no existe en nuestro medio un desarrollo jurisprudencial permanente y sostenido sobre responsabilidad civil de los empresarios proveedores por daños causados en las relaciones de consumo, por ello podemos señalar sin temor a equivocarnos que estos temas aún son extraños a los jueces peruanos.

Es preciso señalar que esta escasa jurisprudencia sobre el tema demuestra también la falta de mecanismos procesales idóneos respecto de las indemnizaciones por daños derivados de la violación de los derechos del consumidor y tal como lo hemos expuesto es preciso proponer figuras como la inversión de la carga de la prueba, los procesos sumarios especiales para este tipo de debates

Anteriormente la responsabilidad civil por defectos de los productos se fundamentaba en el artículo 1970 del Código Civil Peruano sobre daños causados por bienes riesgosos o peligrosos que estatuía la responsabilidad civil objetiva, sin embargo, dadas las características de la sociedad moderna, como la producción masiva y la contratación de consumo, motivaron que el tratamiento de la responsabilidad civil objetiva se vaya especializando en materia de 
consumidor, por ello ahora ya no es necesario recurrir a la norma del código, toda vez que existe una norma especial que se aplica a todos los casos en que existen daños a los consumidores ocasionados por defectos de los productos comercializados en el mercado, aunque es obvio que los grandes principios de la teoría general de la responsabilidad civil, estarán siempre inmersos en todo razonamiento sobre el tema. El Derecho del Consumidor también persigue la prevención de los posibles daños a los consumidores, de ahí que existen leyes y directivas que apuntan a ese objetivo como es el caso de las medidas correctivas que el Indecopi está facultado a otorgar y que en el fondo buscan desincentivar conductas generadoras de daños a los consumidores.

La doctrina actual acepta que la responsabilidad civil no puede estudiarse y analizarse solamente como un problema de dos actores, un causante de un daño y la víctima, sino que se necesita de una visión integral del fenómeno, es decir una visión totalizadora de las relaciones de consumo en el mercado, porque los daños derivados de ellas, por el riesgo difuso en toda la sociedad, pueden afectar a toda la comunidad de consumidores en general. En este sentido la doctrina italiana entiende que la responsabilidad civil debe ser estudiada desde dos perspectivas: una microeconómica, que permita comprobar la forma como se manifiestan los elementos de la responsabilidad civil en una vinculación intersubjetiva; y una macroeconómica, a partir de la cual se analice las funciones de la responsabilidad civil.

Creemos que sea cual fuere el modelo económico social en el que opere la norma sobre protección de los consumidores, un adecuado sistema de responsabilidad civil en esta materia es aquel que es capaz de articular armónicamente la función preventiva de daños y perjuicios en el mercado, la función compensatoria y reparadora de los daños para beneficio de las víctimas, la función represora o punitiva para sancionar adecuadamente a quienes incumplen la ley y desincentivar las conductas ilícitas.

Algunos autores proponen una visión moderna de la responsabilidad civil y aluden a una visión económica propia de la corriente del Análisis Económico del Derecho, cuyo propulsor, Guido Calabresi, establece que además de la compensación a las víctimas y la desincentivación de conductas, lo más importante es la reducción de los costos administrativos inherentes a todo sistema de responsabilidad civil. En efecto, creemos que lo importante es tener una visión sistémica que sea capaz de nuclear los principios de la teoría de la responsabilidad civil objetiva en relación con los fenómenos derivados de las relaciones de consumo, donde se busque reparar a los consumidores por los daños causados, prevenir las conductas infractoras y promover un mercado transparente para una eficiente asignación de recursos en la sociedad. En este contexto, la doctrina del Derecho Civil ha iniciado una revisión sus instituciones contrastándolas con la realidad económica donde opera la norma y a pesar de que existen frondosas legislaciones sobre protección al consumidor en el ámbito administrativo, la doctrina señala que se requiere contar con una legislación civil que responda a las complejas situaciones que se presentan en las relaciones de consumo, por ello creemos que es innegable la transformación o en todo caso la complementación del Derecho Civil a consecuencia de las normas de protección del consumidor cuya vigencia en todo el sistema jurídico viene provocando una especie de revolución en el campo del Derecho contractual. 


\section{CONCLUSIONES}

1. Hay una crisis de la contratación civil clásica estructurada sobre bases romanistas y el Código Civil Francés de 1804. Los principios que sirvieron para edificar la teoría clásica de la contratación civil son insuficientes para regular las relaciones del contrato de consumo.

2. Surge la disciplina del Derecho del Consumidor con una nueva cosmovisión para regular los conflictos derivados de la contratación masiva propia de un mercado como el de hoy creciente y extendido.

3. El consumidor es la parte débil en el contrato de consumo; su debilidad es estructural, es decir, responde a su ubicación en el mercado y a la lógica de éste. Esta debilidad se funda en un déficit de negociación, déficit de reflexión y sobre todo déficit de información.

4. Se supera el principio de la relatividad del contrato, desde que no sólo el consumidor contratante le puede exigir al proveedor el cumplimiento de sus obligaciones, sino también quien, aunque no contratando con él, consuma el bien o utilice el servicio.

5. Surgen figuras legales que se apartan de la contratación clásica, como la oferta al consumidor, la revocación de ciertos contratos de consumo, la facultad del consumidor de resolver unilateralmente el contrato de crédito al consumidor, la interpretación a favor del consumidor en los contratos de consumo, el principio pro consumidor como pauta hermenéutica para resolver conflictos de consumo

6. Por último, consideramos indispensable que el Código Civil regule, aunque de modo genérico, la contratación de consumo, sobre todo en aquellos países que no cuentan con una legislación especial de protección y defensa del consumidor.

Lima, Enero 17 de 2013. 


\section{BIBLIOGRAFÍA}

Código Civil Peruano de 1984

Código de Protección y Defensa del Consumidor del Perú, Ley 29571 de 02 de setiembre de 2010

Constitución Política del Perú de 1993

DE LA PUENTE Y LAVALLE, M., CÁRDENAS QUIROZ, C. \& CAMACHO GUTIÉRREZ.(2000). Cláusulas Generales de Contratación, En Contrato y Mercado. Lima: Gaceta Jurídica.

De la Puente y Lavalle, Manuel (1995). Las Cláusulas Generales de Contratación y la Protección del Consumidor, Themis, Revista de Derecho, Segunda Época, 51-64.

Diez Picazo, Luis (1996). Fundamentos del Derecho Civil Patrimonial, Madrid: Civitas. Directiva 87/577 sobre protección de los consumidores en el caso de contratos negociados fuera de los establecimientos comerciales, del 20 de Diciembre de 1985.

Directiva 93/13 CEE del Consejo de las Comunidades Europeas sobre cláusulas abusivas en los contratos celebrados con los consumidores, del 5 de Abril de 1993

Gutiérrez Camacho Walter (2004). Derecho de Consumo, Constitución y Contratante Débil, Diálogo con la Jurisprudencia, Año 9, 5

Ley Argentina de Defensa del Consumidor 24.240

Ley Española de Defensa de los Consumidores y Usuarios 26/1984

Ley Española sobre Condiciones Generales de Contratación, 7/1998

MIRABELLI, Giuseppe (1980). Dei Contratti in Generale, Torino: UTET.

RIPERT Georges (1951). El Régimen Democrático y el Derecho Civil Moderno. Puebla

TABOADA Córdova, Lizardo (2000). Elementos de la Responsabilidad Civil. Lima: Grijley.

VEGA MERE, Yuri (1996). Oferta, Información y Consumidor. Lima: Gaceta Jurídica

WOOLCOOT OYAGUE, Olenka (2001). Apuntes y Reflexiones sobre el Régimen de Responsabilidad Civil del Productor. Advocatus. Nueva Época, 5. 